\title{
ERASMO DE ROTTERDAM: EL DIOS TERMINVS Y LA MUERTE
}

\author{
Abdón Moreno García \\ Centro de Investigadores - Iglesia de España en Roma
}

\section{RESUMEN / ABSTRACT}

La muerte tiene una gran importancia en la vida y en el pensamiento de Erasmo de Rotterdam. En la literatura renacentista el Ars Moriendi es un tema de enorme actualidad que se manifiesta en el anillo y la medalla de Erasmo, con el dios Terminvs y el Cedo nulli (No cedo ante nadie), que fueron objeto de diversas interpretaciones.

The death has a great importance in the life and the thought of Erasmo de Rotterdam. In Renaissance Literature the Ars Moriendi is a subject of the enormous present time that pronounces in the ring and the medal of Erasmo, with the God Terminus and Cedo nulli (I do not yield before anybody), that was object of diverse interpretations.

El Renacimiento tenía un gusto muy especial por la Emblemática. De esa realidad deriva que mucha tinta se haya llevado el estudio e interpretación del emblema y el sello de Erasmo. Un simbolo importante en el emblema de Erasmo es el dios Término, uno de los dioses menos conocidos de la mitología romana y mucho menos divulgado. Término era el dios protector de las lindes, de los mojones que separaban las propiedades de los agricultores, costumbre popular que llega hasta nuestros días. Se le representaba como una gran piedra con la que se delimitaban los campos. Para los romanos, el dios Término era el símbolo de la solidez de las fronteras del Imperio, y adquiere un significado 
más general para representar la solidez y la constancia. Esta divinidad está representada y reproducida en el sello que Erasmo utilizaba para sellar las cartas, y en su medallón, que regalaba a sus mejores amigos ${ }^{1}$.

La tinta que se haya llevado el estudio e interpretación del emblema de Erasmo, y la variedad de interpretaciones, me recuerda una noticia reciente:

En 1995, varios físicos agruparon las cinco teorias de las supercuerdas bajo la denominación de Teoria-M, una teoría universal que unificaba las cinco teorias existentes hasta entonces afirmando que en realidad cada una de aquellas no era más que un aspecto diferente de una sola teoria. En esta Teoría-M se identifican 11 dimensiones duales, es decir, 22 dimensiones en donde la supergravedad interactúa entre membranas dimensionales. Esta noticia, en realidad, no hacía más que confirmar algo que los místicos ya sabían, y que ellos habian presentado, mil años antes, bajo la metáfora de los veintidós pétalos de la Rosa Cruz cabalística, que corresponden a las veintidós letras del alfabeto hebreo y a los veintidós senderos del Árbol de la Vida².

Ciertamente, la teoría de la supergravedad no la conocía la Kavala judia, ni la mística medieval, pero los 22 senderos del árbol de la vida eran otra manera de nombrar las supercuerdas, para entender el misterio del universo. Algo así sucede con Cedo nulli de Erasmo. Cada uno lo nombra y lo entiende a su manera. Hasta aquí una captatio benevolentiae para provocar al lector, que es un

WIND, E., La elocuencia de los simbolos: Estudios sobre arte humanista, Madrid 1993; BATAILlON, M., Erasmo y España, México 1966, p. 324s.; FRANSEN. B., "Erasmo, Término y la muerte. Letras e imágenes en diálogo", en Erasmo en España. La recepción del humanismo en el primer Renacimiento español, (Salamanca 26 sept. 2002 a 6 enero 2003), SEACEX, Salamanca 2002, pp. 40-47; HALKIN, L. E., "Érasme et la mort", en Revue de l'histoire des religions 3 (1983) p. 277s.; VANDEN BRANDEN, J. P., "Érasme et la mort", Revue de thanathologie de Paris 89-90 (1992) pp. 47-65; VAN DIEVOET, A., "Concedo nulli", en Miscelanea Jean-Pierre Vandem Brandem: Erasmus ab Anderlaco, Bruselas 1995, pp. 429-438.

2 Sobre estas ideas, se construyó $M$, la tercera novela ex-perimental del autor anarquista: ORIHUELA, A., M, Calumnia ediciones, Moguer 2016. 
principio elemental de la retórica clásica ${ }^{3}$, o dicho para el vulgo: el intentar centrar la atención del iniciado.

\section{LA MUERTE EN ERASMO}

Sin duda la muerte tiene una considerable importancia en la vida y en el pensamiento de Erasmo. En la literatura renacentista el Ars moriendi es un tema de enorme actualidad, y es una suerte de Manual para la preparación y el acompañamiento de la muerte. La muerte era en la época de Erasmo un asunto importante, tanto en el arte como en la literatura sobre este tema. En el arte la encontramos bajo la figura de un esqueleto, una calavera, un monstruo horrendo, un reloj de arena, un espejo, una guadaña, etc.

Erasmo se había enfrentado a la muerte a temprana edad; con trece años muere su madre y poco después su padre. Él mismo consiguió una edad muy avanzada para su época: setenta años. Se queja en más de una ocasión de la vejez y de las dolencias que acarrea, como en un poema de 1506 en el que escribe que volverse viejo no es otra cosa que morir despacio 4 . Y en su Coloquio Funus escribe: "El camino hacia la muerte es mucho más doloroso que la muerte misma"5.

Erasmo mismo hace su testamento en tres ocasiones (1527, 1533, y 12 Febrero 1536 pocos meses antes de su muerte). En carta manuscrita a su amigo Servatius Rotger, Erasmo se queja de su mala salud y de los pocos años que le quedan de vida. También hace el firme propósito de dedicar el tiempo de vida que le queda a la meditación sobre la muerte ${ }^{6}$ y a la preparación de su

3 PÉREZ CUSTODIO, Mª V ${ }^{\mathrm{a}}$., (Ed $\left.{ }^{\mathrm{a}}\right)$, Los Rhetoricorvm Libri Qvatvor de Benito Arias Montano, Antverpiae 1569, Badajoz-Cádiz 1994.

4 De Senectute, versos 28-29. El poema fue escrito en 1506, cuando él contaba apenas cuarenta años.

5 HALKIN, L. E., "Érasme et la mort", en Revue de l'histoire des religions 3 (1983) p. 277. refiriéndose a ALLEN, P. A., Opera omnia Desiderii Erasmi Rotterdami, T. I-3, Clarendon Press, Oxford 1958, p. 538; Cfr. Idem, "Erasmus Servant-Pupils", en ALLEN, P. A., Lectures and Wayfaring Sketches, Oxford 1934, pp. 99-108.

6 KOLS, E. W., "Meditatio mortis chez Pétrarque et Érasme", en Colloquia erasmiana turonensia. Tours 3-25 julio 1969. (Ed.) MARGOLIN, J. C., París 1972, pp. 303311; VANDEN BRANDEN, J. P., "Érasme et la mort", Revue de thanathologie de Paris, 89-90 (1992) pp. 47-65. 
propio óbito. En los treinta años de vida que todavía le quedan, tuvo ocasión de escribir varias obras sobre la muerte, entre las que destacan: Declamatio de morte (1517), Epistola de morte (1523), algunos Colloquia (Funus 1526, Exequiae seraphicae 1531, y Epicureus 1533), y finalmente su De preparatione ad mortem (1534). Este último es el más extenso y también el más completo de sus escritos sobre la muerte; está concebido dentro de la tradición de los Ars moriendi, pero rompiendo con algunos usos y costumbres medievales anticuados sobre la muerte ${ }^{7}$.

\section{EL POLÉMICO EMBLEMA DE ERASMO}

El sello de Erasmo representa el busto de un hombre joven, asentado sobre una piedra cuadrada con la inscripción Terminus, y el lema Cedo nulli (No cedo ante nadie). Falta documentación sobre el sello, no se sabe ni el artífice ni la fecha de su ejecución.

Mucho mejor se conoce la historia del medallón de Erasmo. fue diseñado en 1519 por el artista de Amberes, Quintín Metsys, del que se conservan diversos ejemplares en bronce y plomo. En el anverso del medallón, excepcionalmente grande (103 y $106 \mathrm{~mm}$.) puede verse un busto del propio Erasmo de perfil, con la inscripción ER(asmus) ROT(erodamus); y en el borde del medallón un texto en griego y latin: THN KPEITT \{scil.EIKONA\} TA $\Sigma$ YTTPAMATA $\triangle$ EIEEI (Sus escritos muestran una imagen mejor), y en latín: IMAGO AD VIVÂ EFFIGIÊ EXPRESSA (Retrato del natural). Al pie se halla el año de fabricación de la medalla: 1519.

Sobre el reverso del medallón encontramos la imagen del dios Terminus: una piedra con la inscripción Terminus y, sobre la misma, el busto de un joven de perfil. El lema Cedo nulli del sello ha sido aquí sustituida por Concedo nulli ${ }^{8}$. Alrededor de la imagen un

7 Véase la edición de VAN HECK, A., Desiderius Erasmus: De praeparatione ad mortem, Leiden 1977, y la reciente edición de la traducción española de Bernardo Pérez de Chinchón de 1535: PARELLADA, J. (Ed.), Erasmo: Preparación y aparejo para bien morir, Madrid 2000.

8 VAN DIEVOET, A., "Concedo nulli", en Miscelanea Jean-Pierre Vandem Brandem: Erasmus ab Anderlaco, Bruselas 1995, pp. 429-438. 
texto griego a la derecha y un texto latino a la izquierda, tomados respectivamente de Estobeo y Horacio: OPA TE $\Lambda \mathrm{O} \Sigma$ MAKPOY BIOY (Considera el final de una larga vida), tomada de la Antología de Estobeo $^{9}$; y MORS ULTIMA LINEA RERÛ (La muerte es la última frontera de las cosas), tomada de las Cartas de Horacio $^{10}$.

Los medallones servían como regalo de amistad para los mejores amigos y como recuerdo de grandes homenajes o solemnidades. Resultaron objetos muy codiciados entre los coleccionistas hasta nuestros días, como lo demuestra que ya en 1524 Erasmo tuviera planes para hacer una nueva edición.

A pesar de todo, el emblema de Erasmo provocó preguntas y también críticas entre sus contemporáneos. Sus adversarios le reprochaban el uso del dios Término, símbolo de constancia y determinación, porque en muchas controversias Erasmo "se escurria" y evitaba tomar partido. También les extrañaba el uso de Cedo nulli en el sello, o Concedo nulli en el medallón, en lo que veían una expresión de vanidad. De ahí deriva que algunos amigos le pidieran una explicación, como hizo Alfonso de Valdés, uno de los secretarios del emperador Carlos V, como hiciera en carta del 23 de noviembre de 1527:

"La gente exige además que de una vez por todas expliques lo que quieres con la imagen con la que siempre sellas tus cartas, y con el lema 'No cedo ante nadie'; el Emperador lo desea saber de todo corazón en aras de la tranquilidad pública..."1.

\section{LA DEFENSA DE ERASMO}

La carta de Alfonso de Valdés recibe respuesta de Erasmo casi un año después, el 1 de agosto de 1528, donde proporciona una información detallada acerca de su emblema ${ }^{12}$. Erasmo empieza

9 El texto griego es una variante de una cita de la Antologia de Johannes Stobaeus 2, 7. una colección de centenares de citas de autores griegos.

10 Esta máxima está tomada de las Cartas de Horacio, libro I, 16, 79.

11 ALLEN, P. S., Opus Epistolarum Des, Erasmi Roterodami...vol. VII, Oxford 1928, $\mathrm{n}^{\circ} 1907$, p. 252.

12 ALlEN, P. S., Opus Epistolarum Des, Erasmi Roterodami...vol. VII, Oxford 1928, $\mathrm{n}^{\circ} 2018$, p. 430-432. 
su carta con gran ironía hacia sus detractores que le acusan de "intolerable arrogancia"; Les reprocha a estos "autodeclarados pilares de la Iglesia" que critiquen "con los ojos cerrados algo que no ven ni comprenden, mientras sólo dan pruebas de su estupidez y malignidad", al poner en su boca las palabras Concedo nulli. Y sigue diciendo: "Si ellos hubieran leído mis obras, o me hubieran conocido mejor entonces sabrian que yo soy cualquier cosa menos arrogante". Erasmo no acepta que esos detractores no hubieran oído hablar del dios Término y les recomienda que deberian haber ido a pedir consejo a los expertos, puesto que deberian conocer al dios Término por las obras de S. Agustín y de S. Ambrosio, Padres de la Iglesia.

Erasmo conocía muy bien los escritos de S. Agustín ${ }^{13}$, ya que ingresó en el Convento agustino de Steyn en 1487, y tenía a su disposición una gran biblioteca. S. Agustín en el De civitate Dei habla cinco veces del dios Término y lo hace en dos contextos distintos. Por una parte, se cuenta la historia de Término al no querer ceder ante Júpiter en el Capitolio (IV, 23 y 29; V, 21). A esta historia ya se refiere Erasmo en su Antibarbari de $1495^{14}$. Por otra parte, el dios Término aparece enfrentado al dios Jano, denominándose a éste initiatior, y al primero terminator (IV, 2 y VII, 7). Así pues a través del Civitate Dei, Erasmo ya conocía los dos significados de Término, uno el de la constancia, otro el del final de la vida con la muerte.

Erasmo entra en la explicación con detalles sobre la historia de Término dentro de la mitología romana: era el dios protector de las lindes de los campos y de las fronteras del Estado romano, y se representaba como una mojonera, el mojón que todavía hoy nuestros agricultores usan para delimitar las lindes de sus fincas. Tal mojón nunca debe ser cambiado de sitio. En Roma el dios Término tenía su propio templo y sus propias fiestas las Terminalia. Cuando los augures expresaron la voluntad divina de que se retirasen del Capitolio todos

13 Para ver la gran influencia de S. Agustín en Erasmo, cfr: DEN BOEFT, J., "Erasmus and the Church Fathers", en The Reception of the Church Fathers in the West: from the Carolingians to the Maurits, Ed. Irena Backus, vol. II, Leiden - New York - Colonia 1996, pp. 537-572.

14 WATERBOLK, E. H., "Een Friese Terminus? Een aspect van Erasmus invloed in het Noorden der Noordelijke Nederlanden", en Handelingen: Nationale Erasmusherdenking, (3-6 junio de 1969), Bruselas 1970, pp. 236-259. 
los templos y todos los cultos, excepto el de Júpiter, Término se negó a abandonar el Capitolio, igual que lo hiciera Iuventus.

Erasmo explica después cómo llegó a conocer por casualidad la existencia de Término cuando contaba unos cuarenta años cuando recibió de su alumno y amigo, Alexander Stuart. hijo natural del rey de Escocia Jacobo IV, un regalo que consistia en varios anillos, entre ellos uno con una gema con la figura de Término (Hoy en el Historischen Museum de Basilea). Erasmo reconoce con sencillez que al principio no sabía a quién representaba la figura en cuestión, pero que un anticuario italiano se lo explicó. El humanista explica que consideró esta señal (omen) como una advertencia "de que su muerte ya no estaba lejos" (non procul abesse vitae terminum). Y para perseverar en esta idea, tomó la costumbre de sellar sus cartas con él, y le añadió la inscripción Concedo nulli. Y explica: "De este modo hice con el dios pagano un símbolo, que me estimulaba a mejorar mi vida, ya que la muerte es ciertamente el limite que no retrocede ante nadie" (Mors enim vere terminus est, qui nulli cedere novit).

Más adelante se refiere al medallón con las dos inscripciones griega y latina: la inscripción griega OPA TE $\Lambda \mathrm{O} \Sigma$ MAKPOY BIOY la traduce Erasmo como Specta finem longae vitae (Considera el final de una larga vida); la inscripción latina Mors ultima linea rerû (La muerte es la última frontera de las cosas), abunda en la significación renacentista del final de la vida y la proximidad de la muerte.

Finalmente, el Humanista dice que a él le gusta el emblema por una doble razón "por un lado, a causa de la alusión a la historia mitológica (ex alusione ad priscam ac celebrem historiam) por otro lado, debido al carácter misterioso propio de los símbolos (ex obscuritate quae symbolis est peculiaris)". Y Erasmo concluye en su carta: "Hasta aquí mi defensa en relación con Término o, más exactamente, en relación con esta bagatela (de lana caprina)".

Nuestro Humanista no se limitó a enviar esta explicación a Valdés, sino que también la publicó enseguida conjuntamente con la Interpretatio in Psalmum LXXXV (Basilea, agosto de 1528) ${ }^{15}$.

15 BATAillon, M., Erasmo y España, México 1966, p. 324. 


\section{LOS ADVERSARIOS}

Luis de Carvajal, franciscano antagonista de Erasmo, en ese mismo año de 1528, escribe la Apología de la vida monástica (Salamanca 1528) ${ }^{16}$; en ella acusa a Erasmo de herejía y no deja de reprocharle su orgullo a causa de la utilización del lema Cedo nulli. La acusación es muy fuerte: "El lema Cedo nulli que lleva en su sello, con la efigie del dios Término es la expresión insolente de un soberbio que no se inclina ni ante un Budé, un Reuchlin, un Clichtowe, un Pico de la Mirándola o un Poliziano, ni ante un Agustín, un Ambrosio o un Jerónimo. ¿En qué consiste pues esa superioridad que fascina a tantos, y los atrae al borde del abismo?...No perdona ni a los doctores en teología, a quienes llama asnos a boca llena, ni a los religiosos, a quienes trata de fariseos y sicofantes, ni a los grandes y los reyes, a quienes presenta como tiranos. No perdona ni siquiera al César"17.

El libro de Carvajal originó tanta alarma entre los simpatizantes de Erasmo, que los Franciscanos retiraron el libro del mercado. Alfonso de Valdés sí envió un ejemplar a Erasmo, con el consejo de ignorar la crítica y no reaccionar ante ella. Pero la advertencia de Valdés llegó demasiado tarde: Erasmo ya disponía de un ejemplar, y reaccionó en abril del mismo año: Responsio ad cujusdam febricitantis libellum.

En su respuesta a Carvajal, en abril de 1529, Erasmo explica una vez más lo que ya había aclarado en su carta a Valdés, a saber, que las palabras Concedo nulli no son pronunciadas por él mismo, sino por la muerte. "Yo mismo, en mi propio nombre, cedo ante cualquiera... Si tú me pides que ceda en nombre de Término, es decir, la muerte, entonces no retrocedo ante leones ni elefantes, no retrocedo ante reyes ni papas, no he retrocedido ni ante los profetas ni ante los apóstoles, y definitivamente, tampoco ante S. Francisco ni ante Cristo" 18 .

16 BATAILLON, M., op. cit. pp. 326-327.

BATAILLON, M., op. cit. pp. 324-325.

18 ALLEN, P. S., Opus Epistolarum Des, Erasmi Roterodami...vol. VIII, Oxford 1928, $\mathrm{n}^{\circ}$ 2126, y VAN DIEVOET, A., "Concedo nulli", en Miscelanea Jean-Pierre Vandem Brandem: Erasmus ab Anderlaco, Bruselas 1995, pp. 429-438, aquí pp. 433-434. 
Algún buen amigo como Paul Volz, un monje alemán amigo de Erasmo, también concede poco crédito a la explicación de 1528: "Tú, con tu Término, nunca retrocederás ante nadie" (Carta del 4 noviembre de 1535$)^{19}$.

Algunos historiadores se preguntan todavía hoy si la explicación que Erasmo dio a Valdés reproduce lo que realmente significaba para él el dios Término. El estudio más preciso sobre el tema es de Edgar Wind ${ }^{20}$ que se sigue reproduciendo hasta nuestros dias. Wind afirma que antes de 1528 el dios Término nunca significó la muerte para Erasmo. La idea inicial de Erasmo sobre el dios romano tiene su origen en las conversaciones que mantuvo en Venecia en 1508 con los humanistas italianos del círculo del famoso editor e impresor Aldo Manuzio, con los que debatió sobre el dios Término. Los autores clásicos allí debatidos, (Gelio, Ovidio, Dionisio de Halicarnaso), como los humanistas coetáneos de Erasmo, (Poliziano y Giraldo), nunca lo mencionan como un símbolo de la muerte, sino como el dios que no quiso retroceder ante Júpiter, cuando éste reclamó el Capitolio exclusivamente para sí. Y es en dicho contexto donde debe buscarse el significado original del emblema, como símbolo de su propia firmeza y constancia intelectual.

El que Erasmo sostuviera en su carta de 1528 que Término simbolizaba para él la muerte, tuvo que ver con la actitud crítica que tuvo la Iglesia Romana con el humanismo. Erasmo debía mostrar mucha prudencia para no ser condenado como Lutero, y no ser anatematizado por la Iglesia y el Imperio. Wind hace notar que el lema de Erasmo Cedo nulli empezó a parecerse peligrosamente a las palabras de Lutero en la Dieta de Worms en 1521: "Hier stehe ich, ich kann nicht anders" ${ }^{21}$. Para esquivar la acusación de vanidad y soslayar las eventuales sanciones de la Iglesia, Erasmo optó en

19 ALLEN, P. S., Opus Epistolarum Des, Erasmi Roterodami...vol. XI, Oxford 1928, p. $248, \mathrm{n}^{\circ} 3069$.

20 WIND, E., "Aenigma Termini", en Journal of the Warburg Institute I, Londres 1937-38, pp. 66-69. Reeditado en inglés y español: WIND, E., The eloquence of symbols: Studies in humanistic art, Oxford 1983; La elocuencia de los simbolos: Estudios sobre arte humanista, Madrid 1993.

21 WIND, E., La elocuencia de los simbolos: Estudios sobre arte humanista, Madrid 1993, p. 130. 
1528 por una explicación de Término más acorde con la visión cristiana generalizada sobre la muerte.

Ahora bien, la teoría de Wind choca con los datos del medallón donde las inscripciones griega y latina tienen que ver con la muerte, y tienen una fecha anterior a 1528, concretamente fue diseñado por Metsys en 1519. A ello hay que añadir un grabado polaco de 1525 , en el que se han añadido a la imagen de Término un conjunto de inscripciones latinas, griegas y hebreas, todas las cuales tienen que ver con la muerte. El grabado ocupa la última página de una edición del Conscribendis epistolis de Erasmo, en Gracovia por el ed. H. Wietor; y muestra en mayúsculas un texto de la Methamorphoses de Ovidio: "Sed scilicet ultima semper expectanda dies homini" (Pero, por supuesto, su último día debe ser aguardado por el hombre); el texto latino minúsculo está tomado de Eclesiastés 7,36: "en todos tus actos considera el final de tu vida, y no pecarás a lo largo de la misma"; el texto griego inferior está tomado de Mat 25,13: "Estad alerta porque no sabéis ni el día ni la hora"; la cita hebrea proviene de Job 14,5: "Visto que sus días están limitados, visto que tú has contado sus meses y que has establecido la frontera que él no podrá atravesar".

Parece más lógica la tesis de $\operatorname{Sider}^{22}$, según la cual Erasmo se habría inspirado en su propia obra en especial en su Paráfrasis a las cartas de S. Pablo en la que pone en boca del apóstol varias veces la expresión Concedo nulli. Y señala Sider que la máxima en cuestión comporta diversos matices, según los diversos contextos y las diversas ediciones (entre 1517-1535), de lo que resulta que Erasmo evoluciona a lo largo de los años en la interpretación de su divisa, y excluye cualquier tipo de oportunismo en la explicación de Erasmo en 1528.

\section{TERMINVS ET IUVENTVS}

Al igual que el lema de Erasmo ha sufrido diversas interpretaciones, tampoco se ha escapado de las mismas la figura del joven que se asienta sobre el mojón de piedra.

22 SIDER, R. D., "Concedo nulli: Erasmus. Motto and the Figure of Paul in the Praphrases", en Erasmus in Inglish, Toronto 1985-1986, pp. 7-10. 
Resulta sorprendente que el hombre mayor barbado del anillo de 1509, fuera sustituido por Erasmus por un joven de ondeados cabellos. Se han dado dos explicaciones al respecto.

La primera explicación (Panofsky, Rowlands, Landolt) sugiere que Erasmo habría llevado a cabo la alteración de la iconografia del anillo después de la muerte de su donante Alexander Stuart, en la batalla de Flodden de 1513, cuando contaba quince años de edad. la muerte de su discípulo le habría afectado tanto que decidió cambiar en su memoria la efigie del anciano por la de un joven.

Una segunda interpretación busca en la mitología romana su fundamentación. En el Capitolio, Término, el dios de los términos y las lindes, estaba acompañado por Iuventvs, el dios de la juventud representado con un joven ${ }^{23}$. El sello y el medallón deben ser interpretados así: el zócalo representa a Término y el busto a Iuventvs. En su carta de 1528, Erasmo dio a su emblema una nueva interpretación más aceptable en términos cristianos, el zócalo con la inscripción Término sería el símbolo de la muerte, y Iuventvs, el de la vida eterna tras la muerte.

Quizás sea posible una tercera vía, propuesta por Nicolas Mallarius ${ }^{24}$, contemporáneo de Erasmo, según la cual el dios Término representa la vida antes de la muerte. En una carta a Erasmo del 1 de febrero del 1531 llama a la figura un humanae vitae symbolum. El joven en la flor de la vida, personifica no sólo la plenitud de la vida terrenal, sino al mismo tiempo su fugacidad. No está muy lejos el símbolo de la vanitas de la calavera ${ }^{25}$.

Resulta muy curioso que el grabado de H. Holbein el Joven de $1538 / 1540$, que originalmente estaba destinado a ser el frontispicio de las Opera Omnia de Erasmo, representa al dios Término de nuevo como un hombre mayor, habiendo envejecido al igual que Erasmo, que está representado detrás del dios de las lindes, que

\footnotetext{
WIND, E., op. cit. ed. castellana, Madrid 1993, p. 129.

4 ALLEN, P. S., Opus Epistolarum Des, Erasmi Roterodami...vol. IX, Oxford 1928, p. $114, \mathrm{n}^{\circ} 2424$.

25 JARDINE, L., Erasmus, man of letters: The construction of charisma in print, Princeton 1993, p. 82.
} 
ya se encuentra más allá de la muerte. Si a S. Jerónimo la vanitas se le representa con la mano apoyada sobre una calavera, aquí la mano de Erasmo descansa sobre Término.

\section{LA MUERTE EN EL THEATRO MORAL (AMBERES 1612)}

El tema de la muerte como final de la vida y la gran igualadora, tiene una gran tradición en el Renacimiento y se alarga hacia el siglo XVII con el desarrollo del neoesticismo ${ }^{26}$. Así pues, la tercera edición cumbre de los grabados (Emblemata) de Otto Vaenius ${ }^{27}$ de 1612, se realiza por Foppens en Bruselas 1672, y lleva por título: Theatro Moral de la vida humana en cien emblemas con el Enchiridion de Epicteto y la Tabla de Cebes philosofo platonico, del cual existen sólo seis ejemplares en España. Este es uno de los libros ilustrados más bellos de la Europa del S. XVII, con numerosas ediciones en varias lenguas, "obra propia para enseñanza de reyes y príncipes" 28 , lo que la inscribe en la corriente y moda pedagógica barroca de los libros de emblemas y empresas dirigidos a la formación ética de los delfines de la corte, en los que la ilustración era tan importante o más que el texto, y cuyos consejos y advertencias entraban por la vista por su belleza, y se adherian tenazmente a la memoria, en gran parte gracias a su propia originalidad. Esa Via pulchritudinis, esa búsqueda de lo bello, tenía un carácter propedéutico fundamental, no es por ello extraño pues que el Papa Francisco ${ }^{29}$ en su última Exhortación insista en ello. La enseñanza sobre la muerte adquiere

${ }^{26}$ Cfr. nuestros ensayos: MORENO GARCÍA, A., "La actualidad sapiencial y ética de los Epigramas (I-XXX) de Diego de Barreda en los Emblemata de Horacio (1612)", Anales Valentinos 76 (2012) pp. 295-317; Idem, "Una lección sapiencial y ética para nuestros dias: Los Epigramas (XXXI-LX) de Diego de Barreda en los Emblemata de Horacio (Amberes 1612)", Boletin Real Academia de Extremadura 20 (2012) pp. 247-288.

27 Tenemos a la vista la edición de 1612: Otto Vaenius, Quinti Horatii Flacci Emblemata (Antverpiae 1612). Impr. Philipum Lisaert. 214 pp;

28 Según consta en el prólogo de la obra. Cfr. MORENO GARCÍA, A., "Saber vivir: La ética del Argumento y breve declaración de la Tabla de Cebes (s. V a. C.)", Helmantica 64 (2013) pp. 7-40; Idem, "Introducción al Theatro Moral de la vida humana: Proemio desta obra y la vida del author (A. Brum 1672)", Helmantica 64 (2013) pp. 147-179.

29 Evangelii Gaudium, n 167. 
en el Theatro Moral una serie de Emblemas que recogen con gran belleza toda la sabiduría estoica y bíblica al respecto.

Los epigramas de Barreda se convierten así en un metalenguaje ${ }^{30}$ siempre dispuesto a desplegar detalles y funciones de una cultura determinada sujeta a cambios a lo largo de los tiempos. A los Epigramas de Barreda de 1612, se unen las glosas introductorias y los epigramas de A. Brum de 1672. Ad casum, nuestra colección sobre la muerte y el tiempo oportuno de la vida, tiene cuenta de los dos autores que se flexionan sobre la experiencia de las canas, como hiciera lo mejor de la literatura sapiencial hebrea y griega. En nuestros dias, los epigramas siguen hablando y el lector de nuestro tiempo asume sobre ellos una paternidad ${ }^{31}$ que perdió el autor hace ya 400 años. Bien es verdad, que "sin la renovación de las artes del lenguaje en la educación ${ }^{32}$, y sin la recuperación del comentario (epigramas, en nuestro ensayo), el humanismo como movimiento cultural no habria sido posible"33.

30 SÁNCHEZ MANZANO, $\mathrm{M}^{\mathrm{a}}$. A., (Ed.), "Introducción", a la Simbología y enigmática en la literatura grecolatina, Ed. Univ, de León / Tecnos, Madrid 2011, p. 14: "A primera vista, el lenguaje verbal puede llegar con su diversidad interminable a describir cualquier signo de una cultura, convirtiéndose en un metalenguaje siempre dispuesto a desplegar detalles y funciones, Por eso resulta especialmente útil para describir códigos más limitados que el propio lenguaje, como los códigos gestuales o las actitudes sociales propias de una convivencia sujeta a cambios a lo largo del tiempo. También éste puede ser el motivo de que a veces se espere del lenguaje verbal más de lo que la intención o el pensamiento del emisor permitía. Entonces el mensaje adquiría una cierta independencia desligado de su emisor y de su contexto comunicativo, sobre todo con ayuda de la escritura. Jugando con la forma, los mensajes pueden sugerir una multiplicidad de sentidos, justificando esa independencia del acto comunicativo en sí, interpelando a quien desee tomarlos, aceptar ese producto social y aprovecharlo. Los medios que sirven para generar comunicación pueden servir igualmente para generar confusión, para jugar, para distraer, para fingir inutilidad comunicativa, opacidad".

31 Es muy conocida la célebre expresión del padre de la hermenéutica moderna, Gadamer, sobre los textos y su fusión de horizontes: "Un texto debe perder la paternidad del autor para adquirir la paternidad del lector".

32 No podemos olvidar que en el prólogo del Theatro Moral... de Bruselas 1672 el prologista lo presenta como una obra para la educación del Principe Balthasar Carlos.

33 SÁNCHEZ MANZANO, $\mathrm{M}^{\mathrm{a}}$. A., "Sabiduría en las artes del lenguaje: Tradición en el siglo XV”, en Idem, (Ed.) Simbología y enigmática en la literatura grecolatina, Ed. Univ, de León / Tecnos, Madrid 2011, p. 238. 
Con la idea erasmiana ${ }^{34}$ de la muerte como la última linde, la última frontera, podemos leer el epigrama 103 del Theatro Moral con un precioso emblema sobre el tema:

Mors ultima linea rerum est. [103]

Todo lo deja el hombre juntamente, Cuando al termino muerte llega, y cuando

Deja de andar aquí peregrinando, Volviendo al polvo, su primera fuente; Que es ley del cielo, y ley, que no consiente, Excepción por riqueza, triunfo, o mando;

Las virtudes tan solo eternizando, Que es lo que el cielo guarda eternamente;

Éstas al fin esperan la corona, Cantando al fin la gloria en dulce canto, Pues vive el hombre solo en su memoria; Y yo también dejando la Elicona, Por lo bueno ${ }^{35}$ diciendo sancto sancto, Al fin eterno cantaré la gloria.

Aquí acaban los mortales su carrera, aquí se dan todos por vencidos, haciendo de la muerte su ilustre compañera. Y aquí se verifica con evidencia como pasa la gloria del mundo; nos lo muestra el buril del emblema presentando a un esqueleto tendido sobre el suelo y así quedan desamparadas y sin dueño a su lado, las coronas, los laureles, los cetros y las insignias consulares. A. Brum nos lo hace ver mejor en La explicación del emblema centésimo tercero:

"Puesto que la muerte es el último término de todas las cosas, razón será que le ponga yo también fin a estos discursos; pues es justo parar donde todos paran. Con cuánta más verdad y fundamento que Hércules, pudiera grabar esta Vencedora del Mundo, en las columnas de su Meta, el non plus ultra: pues no pasó ninguno de ella. Aquí quedan, desamparadas y sin dueño, las Coronas, los Laureles y las Insignias Consulares; y se mezclan confusamente con las Prisiones, los Azotes, los Trabajos y las

34 HALKIN, L. E., "Érasme et la mort", en Revue de l'histoire des religions 3 (1983) p. 277s.; VANDEN BRANDEN, J. P., "Érasme et la mort", Revue de thanathologie de Paris 89-90 (1992) pp. 47-65.

35 En la edición de 1672: "Acabaré diciendo...". 
Miserias. Aqui acaban todos los mortales su carrera. Aqui se dan todos por vencidos. Y aquí se verifica, con evidencia, cómo pasa la gloria de este Mundo. Consideremos, por otra parte, la Virtud, que es la única que pasa de este término fatal; y como su origen es del Cielo, donde la Muerte no tiene imperio, se muestra triunfante de la universal Tirania. Y nos enseña que sólo la parte inferior y corruptible del Hombre perece; y que la Superior ha de habitar con ella eternamente, en virtud de sus buenas obras y de los méritos de la preciosisima Sangre de Jesucristo, Redentor nuestro, a quien proclamo de corazón que someto este pequeño estudio al examen, y corrección de nuestra Santa Madre la Iglesia Romana, deseando vivir y morir en su gremio, y bajo su obediencia: $y$ quedo pronto a firmarlo con mi Sangre"36.

Ponga el punto final el último epigrama que nos ofrece nuestro humanista Antonio Brum ${ }^{37}$, comentando el mote del emblema: Mors ultima linea rerum est (La muerte es la última línea de todo):

\author{
Este es el fin de tu suerte \\ Peregrino! Si reparas, \\ Que los cetros y tiaras, \\ Todo yace con la muerte \\ No pierdas tiempo, y advierte: \\ Que en lo que es mortal no esperes; \\ $\mathrm{Y}$ que siempre consideres \\ En el cadáver que ves: \\ Que tú serás lo que él es. \\ Como él fue, lo que tú eres.
}

En el epigrama 93, "Vivamos de manera que no temamos la muerte", nos insiste en la idea estoica del saber vivir como actitud fundamental del hombre sabio, que no teme ni la muerte ni la vida:

36 El texto del epigrama y la explicación los hemos castellanizado, dada la dureza del original para el lector no iniciado, y según aconseja la paleografia actual; sin embargo, hemos respetado el uso de las mayúsculas dado el frecuente uso mitológico.

37 Puede verse un largo recorrido por la biografia de A. Brum en el proemio de la edición de 1672 que hemos publicado recientemente en Helmantica: MORENO GARCÍA, A., "Introducción al Theatro Moral de la vida humana: Proemio desta obra y la vida del author (A. Brum 1672)", Helmantica 64 (2013) pp. 147-179. 
Sic vivamus, ut mortem non metuamus. [93]

Que os admiráis de las canas, Y de esa arrugada frente, Si corren continuamente Mañanas, y más mañanas? No en balde pasan ufanas horas tras horas, y exhorta La religión, que en la corta Vida vivamos bien, y advierte, Que para vivir en muerte, Solo el saber bien vivir importa.

En este emblema se nos muestra a un hombre mirándose al espejo, y admirando sus arrugas y sus canas, mientras van entrando por la puerta la senectud y la muerte. Pero aunque ha vivido bien no se halla aún resuelto a recibirlas, y presume que la Religión que está a su lado le ha de salvar. Mas ella, como una gran matrona romana, le dice que no los puede detener, y le amonesta que trate de partir porque ya ha llegado el tiempo, pues penden sobre su cabeza los años que pasaron con velocidad de aves, y ligereza de ciervos.

El mote del emblema sic vivamos ut mortem non metuamus (Vivamos de manera que no temamos la muerte), lo comenta Brum en la p. 189:

Cuando a conocer se acierta la perdida juventud;

sin que el mísero lo advierta, van entrando por la puerta

la muerte y la senectud.

De nuevo cambia la posición del emblema, aquí 94, en la edición de 1612 lleva el $\mathrm{n}^{\circ}$ 93. Brum introduce La explicación del emblema nonagésimo cuarto:

"Procuremos vivir de manera que la Muerte no nos coja descuidados. El que tiene buena conciencia, y considera que cada día puedes ser el último de su vida, sabe, más ciertamente que el Astrólogo, cuál será la hora de su muerte. Y además de ser grandísima ignorancia creer que haya ciencia humana que pueda penetrar los inescrutables secretos, 
escritos con el dedo de la divina Omnipotencia en el Libro de la vida: presupongo que el pronóstico te pueda revelar el cómo de tu fin, y que tú lo creas; vienes a ser mucho más miserable, pues siempre vives con temor y aprehensión de un cómo, del que ignoras el cuándo, que es lo principal. Las Historias están llenas de ejemplos de aquéllos que, procurando evitar semejantes adivinaciones, han acelerado por otro camino su muerte. Conviene (sin hacer caso de estas supersticiones) imitar al sabio Piloto, que apresta su nave para cuando se ofrezca el tiempo de su partida. En este Emblema se nos muestra un hombre mirándose al espejo, y admirando sus arrugas y sus canas; $y$ que se le van entrando, por la puerta, la Senectud y la Muerte. Pero aunque ha vivido bien, no se halla aún resuelto a recibirlos; y presume que la Religión, que está a su lado, le ha de salvar. Mas ella les dice que no los puede detener, y le amonesta que trate de partir porque ya es tiempo, pues penden sobre su cabeza los años, que pasaron con velocidad de aves y ligereza de Ciervos. Esto nos significa que muchos piden a Dios prolongación de su vida, cuando habian ya de estar dispuestos a la muerte".

Y en el emblema 98 tenemos la certeza de la muerte a cuya "oficina" acuden todos los mortales, y que van allá todos en tropa sin diferenciarse los reyes de los vasallos:

Mortis certitudo. [98]

Si es fuerza acudir todos

A la triste oficina de la muerte,

Que por diversos modos

O más corta, o más larga da una suerte,

$¿$ En que nos confiamos

Si de prestado en esta vida estamos?

La más bella hermosura,

La juventud del mundo más lozana,

Ya en agraz, ya madura,

Con la vejez la embarca esta tirana,

Que un flaco fundamento

Le deshace sin manos cualquier viento.

La explicación del emblema nos ayuda a profundizar en como la muerte reparte a todos los mortales, sin distinción de calidad, sexo o edad, el pasaporte para que vayan al lugar que Dios les tiene destinado. Parece que nos pinta aquí la muerte dando a todos por igual este mismo portazgo, para darnos a conocer que las riquezas de esta vida no sirven de nada en el otro mundo, y que van allá todos 
en tropa, sin diferenciarse los reyes de los vasallos, los pobres de los ricos y los mozos de los viejos; ni los enfermos, ciegos y tullidos, de los robustos y sanos.

El mote mortis certitudo (La certidumbre de la muerte) y el emblema recoge estupendamente el significado, que con una buena sintesis, ha producido certeramente un nuevo epigrama en nuestro humanista Brum en la p. 199:

De qué servirá el caudal,
Que amontonas de continuo?
Viendo que todo mortal,
Lleva la porción igual,
En el último camino.

Las resonancias de Qohélet 3,18-21, en este emblema y epigramas, son evidentes: La muerte es la gran igualadora de la vida, ella también habita en los sepulcros de mármol. Ricos y pobres, torpes y listos, sabios y necios (Qoh. 2,14-16) ${ }^{38}$ no pueden resistirse a su imperio. La muerte ridiculiza y se befa de todos los valores más nobles y amados. Lo señala Brum con La explicación del emblema nonagésimo nono:

"Tiene más de fabuloso y poético este Emblema que de Moral; y nos representa la muerte, repartiendo los Pasaportes, a todos los mortales igualmente -sin distinción de calidad, sexo ni edad-para que vayan al lugar que Dios les tiene destinado, a cada cual, en el otro Mundo. Por otra parte alude al ciego error de los antiguos, que a todos los que morian (de cualquier calidad que fuesen) les metian en la boca un Óbolo (moneda asi llamada) para pagar el pasaje de la Barca, por los Ríos Infernales -Aqueronte, Cocito y Estigio- al que otros añaden el Flegetonte y el Averno. Parece que se nos pinta aqui la Muerte, dando a cada cual este mismo portazgo (que es muy tenue) para darnos a conocer que las Riquezas de esta vida no sirven de nada en el otro Mundo; y que van allá todos en tropa, sin diferenciarse los Reyes de sus Vasallos; los Pobres

38 "No hay recuerdo duradero ni del sabio ni del necio; al correr de los días todos son olvidados, pues el sabio muere igual que el necio. He detestado la vida, porque me repugna cuanto se hace bajo el sol, pues todo es vanidad y atrapar vientos" (Qoh. 2,16-17). Horacio mantiene la misma idea: "Pallida mors aequo pulsat pede, pauperum tabernas regumque turres", (Lib. 1, Od. 4). 
de los Ricos; los Mozos de los Viejos; ni los Enfermos, Ciegos y Tullidos de los Robustos y Sanos. Y aunque sobre semejantes ficciones se ofrece harto poco que discurrir, no falta materia para meditar, y sacar mucho fruto, de la memoria y certidumbre de la muerte".

A la postre ${ }^{39}$, veamos como el gran humanista Saavedra Fajardo ${ }^{40}$ puso un epitafio final a sus Empresas politicas en la primera edición de 1640, pocos años antes de la edición del Theatro Moral que nos ocupa, y que llevaba por mote Lvdibria mortis (Los ultrajes de la muerte). El emblema presenta unas ruinas de noble construcción, donde aparecen abandonados un cetro, una corona real, y lo que parece la calavera de un rey, cuya parte superior muestra la red tupida de una telaraña. Muestra así como la muerte iguala a todos los mortales, ricos o pobres, poderosos y arrogantes o sencillos y humildes y lo explica en su epigrama:

Este mortal despojo, oh caminante,

triste horror de la muerte, en quien le araña

hilos anuda y la inocencia engaña, que a romper lo sutil no fue bastante, coronado se vio, se vio triunfante con los trofeos de una y otra hazaña, favor su risa fue, terror su saña, atento el orbe a su real semblante.

Donde antes la soberbia, dando leyes a la paz y a la guerra presidía se prenden hoy los viles animales. ¿Qué os arrogáis, ¡oh príncipes, oh reyes!

si en los ultrajes de la muerte fría comunes sois con los demás mortales?

39 Si el iniciado quiere ampliar la visión de la muerte en el Renacimiento Cfr. nuestro estudio: "La muerte es la gran igualadora: Una tradición humanística y bíblica en el Theatro moral de la vida humana (Amberes 1612)", Revista de Estudios Extremeños. Homenaje al $350^{\circ}$ Aniv. del Seminario Metropolitano, 70 (2014) pp. 809-852.

40 SAAVEDRA FAJARDO, Diego, Empresas politicas, (Ed. de Sagrario López Poza), Madrid 1999, Ed. Cátedra, Letras Hispánicas, pp. 1048-1049. Cfr. SOLÓRZANO PEREIRA, Juan de, Emblemas regio-politicos, Ed. de J. M. González de Zárate, Ed. Tuero, Madrid 1987. 
Los estudios sobre la convergencia entre cultura artística y expresiones estéticas dela fe pueden ser realizados de múltiples modos, y desde múltiples perspectivas académicas y condicionamientos históricos ${ }^{41}$. El Papa Francisco ${ }^{42}$ insiste en ello: "Es bueno que toda catequesis preste una especial atención al "camino de la belleza" (via pulchritudinis). Anunciar a Cristo significa mostrar que creer en Él y seguirlo no es sólo algo verdadero y justo, sino también bello, capaz de colmar la vida de un nuevo resplandor y de un gozo profundo, aun en medio de las pruebas. En esta línea, todas las expresiones de verdadera belleza pueden ser reconocidas como un sendero que ayuda a encontrarse con el Señor Jesús. No se trata de fomentar un relativismo estético, que pueda oscurecer el lazo inseparable entre verdad, bondad y belleza, sino de recuperar la estima de la belleza para poder llegar al corazón humano y hacer resplandecer en él la verdad y la bondad del Resucitado. Si, como dice san Agustín, nosotros no amamos sino lo que es bello, el Hijo hecho hombre, revelación de la infinita belleza, es sumamente amable, y nos atrae hacia sí con lazos de amor. Entonces se vuelve necesario que la formación en la via pulchritudinis esté inserta en la transmisión de la fe... en orden a transmitir la fe en un nuevo "lenguaje parabólico". Hay que atreverse a encontrar los nuevos signos, los nuevos símbolos, una nueva carne para la transmisión de la Palabra, las formas diversas de belleza que se valoran en diferentes ámbitos culturales, e incluso aquellos modos no convencionales de belleza, que pueden ser poco significativos para los evangelizadores, pero que se han vuelto particularmente atractivos para otros".

Encontrar "una nueva carne" para la trasmisión de la Palabra, un "nuevo lenguaje parabólico", exige un intenso diálogo con la cultura de nuestro tiempo sin paternalismos ni imposiciones.

No es fácil apreciar un arte o una cultura plenamente ateas, "hemos sido por mucho tiempo, y creo que todavía lo somos, los

41 JIMÉNEZ CATAÑO, R. - GARCÍA-NOBLEJAS, J. J., (Eds.), Poetica \& cristianesimo, Ed. Univ. Santa Croce, Roma 2004, p. 10. Cfr. Dos perspectivas diversas recientes: GONZÁLEZ VALERIO, M. A., "Estética y hermenéutica. El problema de la referencia en el relato de ficción”, Est. Filos. 54 (2005) pp. 313-332; CASTRO, S. J., "Estética y hermenéutica analógica", Est. Filos. 54 (2005) pp. 333-355.

42 Evangelii Gaudium, n 167. 
huéspedes de la creación. Debemos a nuestro anfitrión la cortesía de la pregunta"43. Ser huéspedes de los mundos posibles, nacidos de la creación artística y literaria, naturalmente, impone extrapolar la referencia al anfitrión que alli nos coloca, y que nos llama a imitarlo libremente como Creador en el mundo real ${ }^{44}$.

El iluminismo racionalista ha roto la relación trascendente con Dios, y quiere dinamitar el ministerio de los pastores del evangelio y la religión que se inserta, pacífica y serenamente, en el núcleo central de la vida pública de la sociedad; la consecuencia es clara: "un autentico eclipse de Dios en nuestra civilización"45.

La Ratio no agota el misterio de la muerte, más bien le desconcierta y le estremece, sin embargo la sabiduría estoica, -aquellos que Erasmo ${ }^{46}$ llamó "cristianos sin revelación"-, aportan un bagaje sapiencial sobre el Ars moriendi, tan de moda en el Renacimiento europeo, que ilumina el mensaje cristiano sobre la vida y la muerte. Quizás nos ayuden a encontrar "una nueva carne" para la trasmisión de la Palabra, un "nuevo lenguaje parabólico", -en este caso epigramas y emblemas, carne y alma, se diría en la época ${ }^{47}$-, que nos exige, a la par que nos facilita, un intenso diálogo con la cultura de nuestro tiempo.

43 STEINER, G., Gramáticas de la creación, Madrid 2001, pp. 15-17.

44 A ello hace referencia Garcia-Noblejas en la presentación del volumen que acabamos de citar: JIMÉNEZ CATAÑO, R - GARCÍA-NOBLEJAS, J.J., (Eds.), Poetica \& cristianesimo, Ed. Univ. Santa Croce, Roma 2004.

45 TAYLOR., Ch., "A Place for Trascendence?", en SCHWARTZ, R., (Ed.), Trascendence, Philosophy, Literature and Theology. Approach the Beyond, New York 2004, p. 8.

46 KOLS, E. W., "Meditatio mortis chez Pétrarque et Érasme", en (Ed.) MARGOLIN, J. C., Colloquia erasmiana turonensia. Tours 3-25 julio 1969, París 1972, pp. 303311; VANDEN BRANDEN, J. P., "Érasme et la mort", Revue de thanathologie de Paris 89-90 (1992) pp. 47-65.

47 SAAVEDRA FAJARDO, D., Empresas politicas, (Ed. de Sagrario López Poza), Madrid 1999, Ed. Cátedra, pp. 23-31. Recordemos que el mismo A. Brum, en el Proemio al Theatro Moral, cita a las Empresas de D. Diego Saavedra Fajardo. 